\title{
A PROPÓSITO DEL MAESTRO DE LOS SANTOS JUANES
}

\author{
POR \\ IRUNE FIZ \\ Departamento de Historia del Arte. \\ Universidad de Valladolid
}

\begin{abstract}
The Master of «The Santos Juanes» is a painter from the middle 1500's whose achievements, studied in this article, are located in several towns of Tierra de Campos. These locations were formerly part if the Leon's diocese. His work is characterized by the great importance given to the atmospheric treatment, both when it consists in countryside views (similar to those seen in the Astorga Master work) or when the backgrounds are architectonic renaissance style interiors. The Master's inspirations are engravings from Dürer and Marcantonio Raimondi. The Juan de Flandes influence is evident all throughout his work.
\end{abstract}

Es éste un maestro poco conocido, cuya identidad estilística ha sido establecida recientemente por Isabel Mateo en las tablas publicadas en tres catálogos de la galería Caylus ${ }^{1}$. En su estilo se advierte claramente su filiación palentina, en concreto con Juan de Flandes y principalmente con dos de sus seguidores, el Maestro de Becerril y el Maestro de Astorga. Esta característica ya fue sugerida por la doctora Mateo al hablar de sus posibles influencias, y se ratifica con el estilo de las tablas que presentamos a continuación. No obstante, los lugares de origen de todas ellas, localizados en Tierra de Campos, pertenecieron en el siglo xvi a la diócesis de León. No es de extrañar, sin embargo, su vinculación con la obra de Juan de Flandes, ya que éste y el palentino Pedro Berruguete marcan las directrices fundamentales por las que se mueve la pintura castellano-leonesa de la primera mitad del siglo XvI.

Antes de empezar a hablar de retablos realizados por el Maestro de los Santos Juanes y que todavía se encuentran in situ, quisiéramos incluir en su catálogo dos tablas asignadas al Maestro de Astorga por Post ${ }^{2}$, San Juan Bautista en prisión y Presentación a Salomé de la cabeza de San Juan. Desconocemos su paradero actual ${ }^{3}$ y cualquier dato físico sobre ellas. El conocimiento de sus medidas, de coincidir éstas con las de las tablas del retablo princeps, apoyaría su inclusión dentro del mismo conjunto, que se ocupa de narrar escenas de la vida de San

\footnotetext{
I Mateo Gómez, Isabel: Catálogo de la galería Caylus, 1993, pp. 34-43, 1997, pp. $36-37$ y 1999.

2 Post, Raymond Chandler: A History of Spanish Painting, vol. IX.II, 1947, p. 563, figs. 218 y 219.

${ }^{3}$ En la monografía de Post no se nos facilita la localización de la primera, mientras que la segunda la ubica en el Art Institute de Chicago.
} 

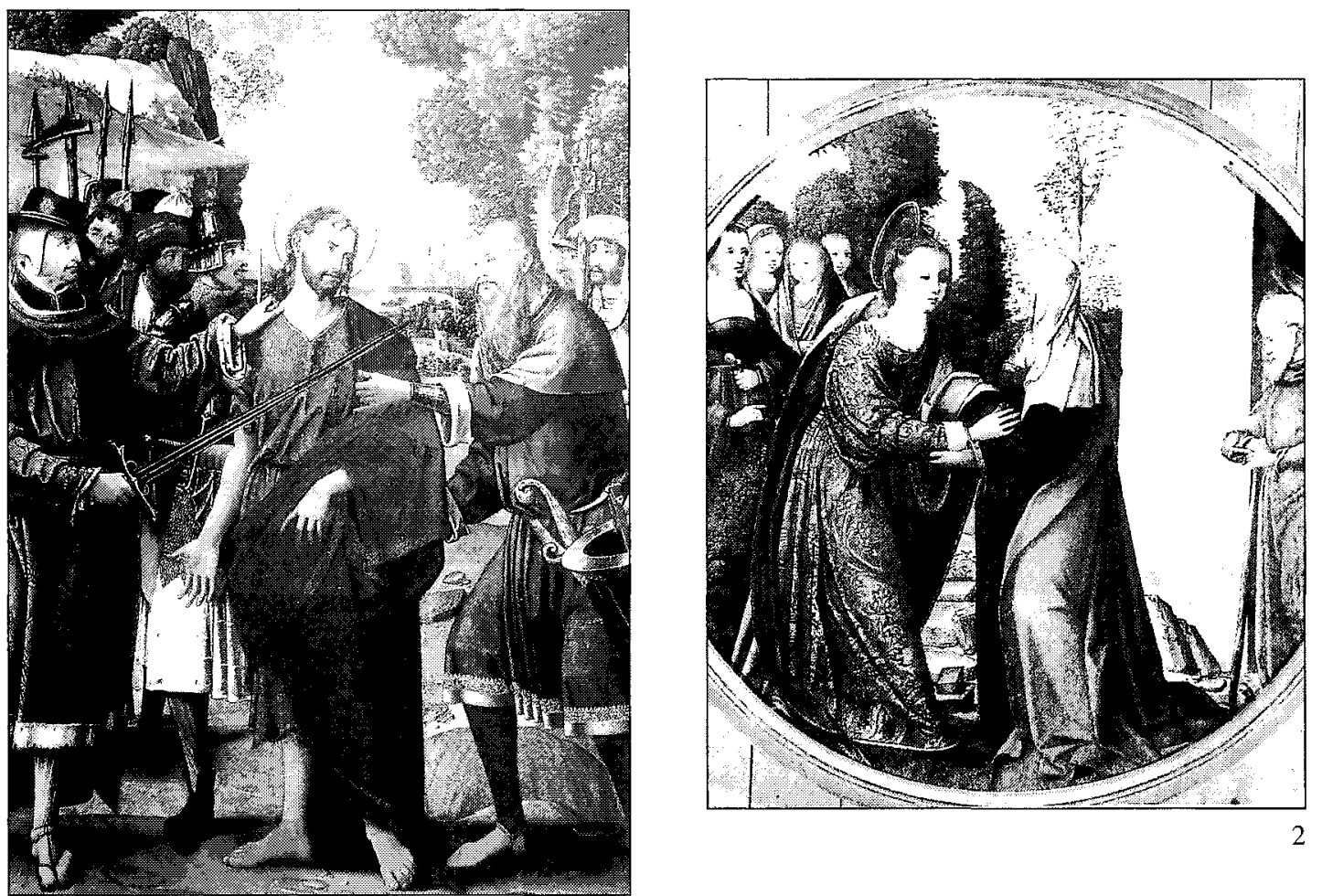

1
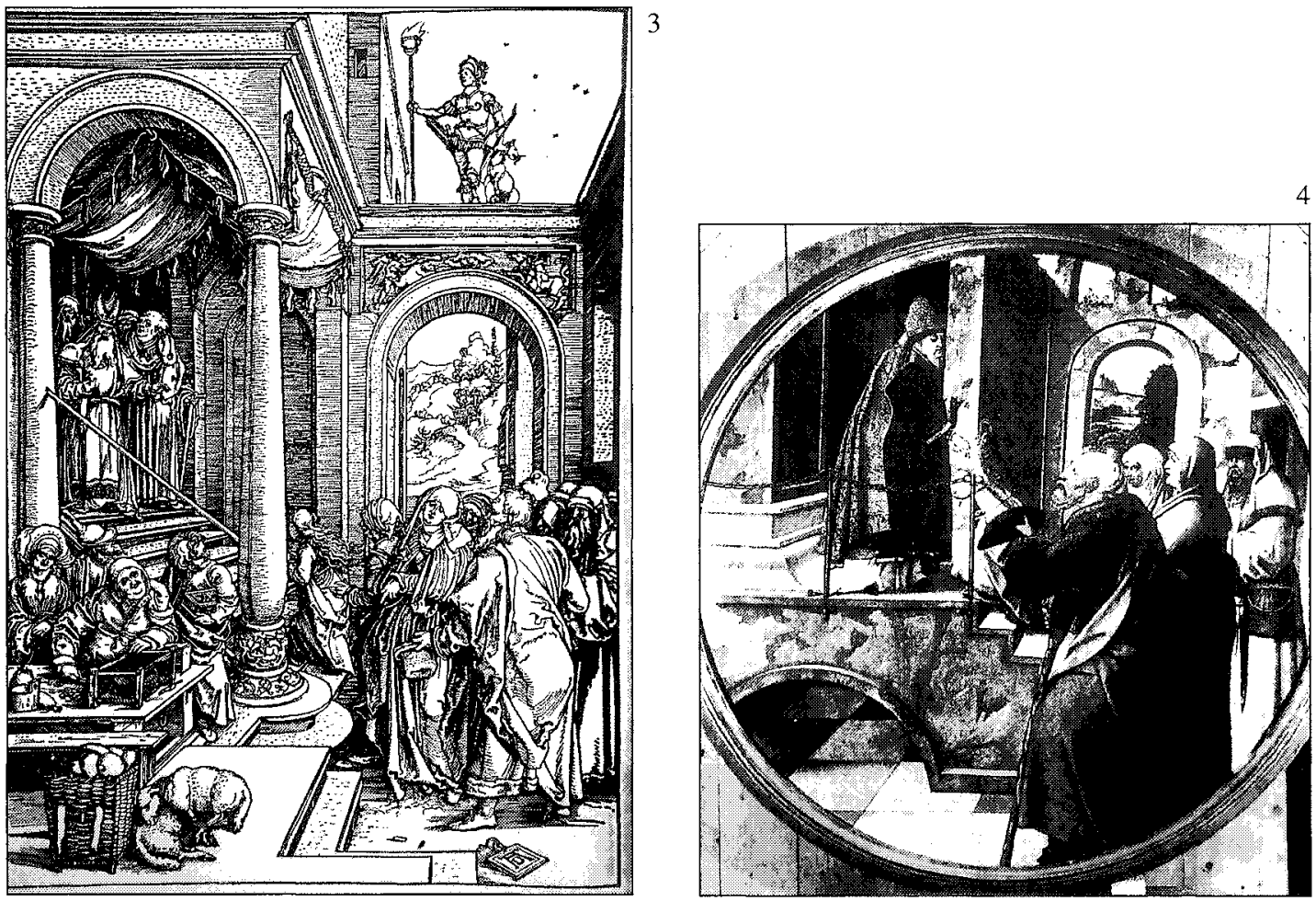

Figs. 1 y 2. Maestro de los Santos Juanes: Prendimiento. Galería Caylus. Visitación. Campazas (León). Fig. 3. Durero: Presentación de María en el templo.

Fig. 4. Maestro de los Santos Juanes: Presentación de María en el templo. Campazas (León). 
Juan Bautista y San Juan Evangelista ${ }^{4}$. La comparación de tipos no deja lugar a dudas sobre la autoría de todas ellas. Salomé y sus doncellas se identifican con la Virgen y la mujer que porta la ofrenda en La Presentación del Niño en el templo del catálogo de Caylus ${ }^{5}$. Respecto al los rostros masculinos, es constante en su obra el situar jóvenes imberbes en un segundo plano, con una media melena, vestidos a la moda de la época. En las tablas reproducidas por Post hallamos sendos ejemplos a la izquierda de cada tabla; en la escena de Juliano el Apóstata haciendo quemar los huesos de San Juan de Caylus ${ }^{6}$, nos volvemos a encontrar en el mismo emplazamiento con un ejemplo de este tipo humano, así como en otras tablas que comentaremos más adelante. Pero los más característicos son los personajes más ancianos, con un perfil aguileño que tiende casi a lo caricaturesco. Esta coincidencia no se da sólo en los rostros, sino también en las proporciones de las figuras, corpulentas, y en los duros pliegues que adornan los ropajes. Encontramos también una concordancia en la composición; las austeras arquitecturas renacientes que adornan el fondo de la escena de Juliano el Apóstata haciendo quemar los huesos de San Juan, enlazan con las que observamos en la escena de San Juan Bautista en prisión; pese a la preocupación de este pintor por el espacio, las escenas no guardan la debida proporción entre la arquitectura y las figuras. Los muros se encuentran demasiado cerca de los personajes y el resultado final es algo ingenuo, poco verosímil. Otra característica de este maestro es el gusto por los tocados masculinos, siendo éstos muy variados: bien siguiendo a la moda del momento (lo que nos ayuda a fechar las obras), bien de corte más exótico, quizá inspirados en los grabados de Durero.

En Campazas (León), se hallaban ${ }^{7}$ en la sacristía de la iglesia parroquial cuatro pinturas cortadas en forma de tondo. El primero en llamar la atención sobre ellas fue Gómez Moreno, quien las incluyó entre la obra del Maestro del Trascoro de la Catedral de Zamora ${ }^{8}$. Post sigue la hipótesis del investigador granadino, puesto que se las asigna a Juan Rodríguez de Solís, identificado según él, con el anónimo Maestro del Trascoro zamorano ${ }^{9}$. Los asuntos que tratan las tablas son la Natividad de la Virgen, la Presentación de Maria en el templo, Anunciación y Visitación. Dado que hoy en día estas tablas se encuentran en manos privadas, no ha sido posible ver la Natividad; afortunadamente, las otras tres se encuentran reproducidas fotográficamente. La Anunciación ha de incluirse entre las obras del pintor más fiel al estilo de Juan de Flandes: su discípulo Juan de Tejerina. Las otras dos restantes se han vinculado a la escuela de Maestro de Astorga ${ }^{10}$. Nosotros pensamos que están más cerca del estilo de nuestro pintor que del Maestro de Astorga y sus colaboradores. Tal vez puedan ser obras tempranas, cuando aún el canon corpulento que acostumbra a utilizar no estaba definido del todo. Pero los rostros son inconfundibles, baste comparar el de la Virgen en la Visitación (fig. 2) con el del mismo

${ }^{4}$ Aunque las tablas incluidas en los catálogos de Caylus sobre el tema del Bautista son tres, El prendimiento de San Juan Bautista, Juliano el Apóstata haciendo quemar los huesos de San Juan y Envenenamiento de San Juan, Isabel Mateo reseña seis tablas más que formaban parte del mismo conjunto: San Juan Bautista ante Herodes, Decapitación del Bautista, Descubrimiento de la cabeza del Bautista, Milagro del intento de envenenamiento de San Juan Evangelista, Milagro de la transformación de guijarros y rosas en oro y piedras preciosas por San Juan Evangelista durante su predicación en Éfeso y Tres monjes benedictinos adorando la cabeza del Bautista. Ninguno de los temas coincide con los de las dos tablas que nos ocupan, por lo que pudieron formar parte del mismo retablo siguiendo rumbos diferentes una vez desmembrado el conjunto.

5 Catálogo de la galería Caylus, 1997, pp. 36-37.

${ }^{6}$ Catálogo de la galería Caylus, 1993, pp. 34-43.

7 Actualmente dispersas en distintas colecciones privadas.

${ }^{8}$ Gómez Moreno, Manuel: Catálogo Monumental de la provincia de León. Madrid, 1925, p. 508.

9 Post, Raymond Chandler: Op. cit. , p.523. Las obras atribuidas a Juan Rodríguez de Solís a partir de dos tablas firmadas por él, fechables a fines del siglo xv, poco tienen que ver con el punto de partida.

${ }^{10}$ Padrón Mérida, Aída: «Una obra del Maestro de Zamora» Antiquaria, n 124, 1995, pp. 82-86, atribuye la Visitación al Maestro de Zamora 

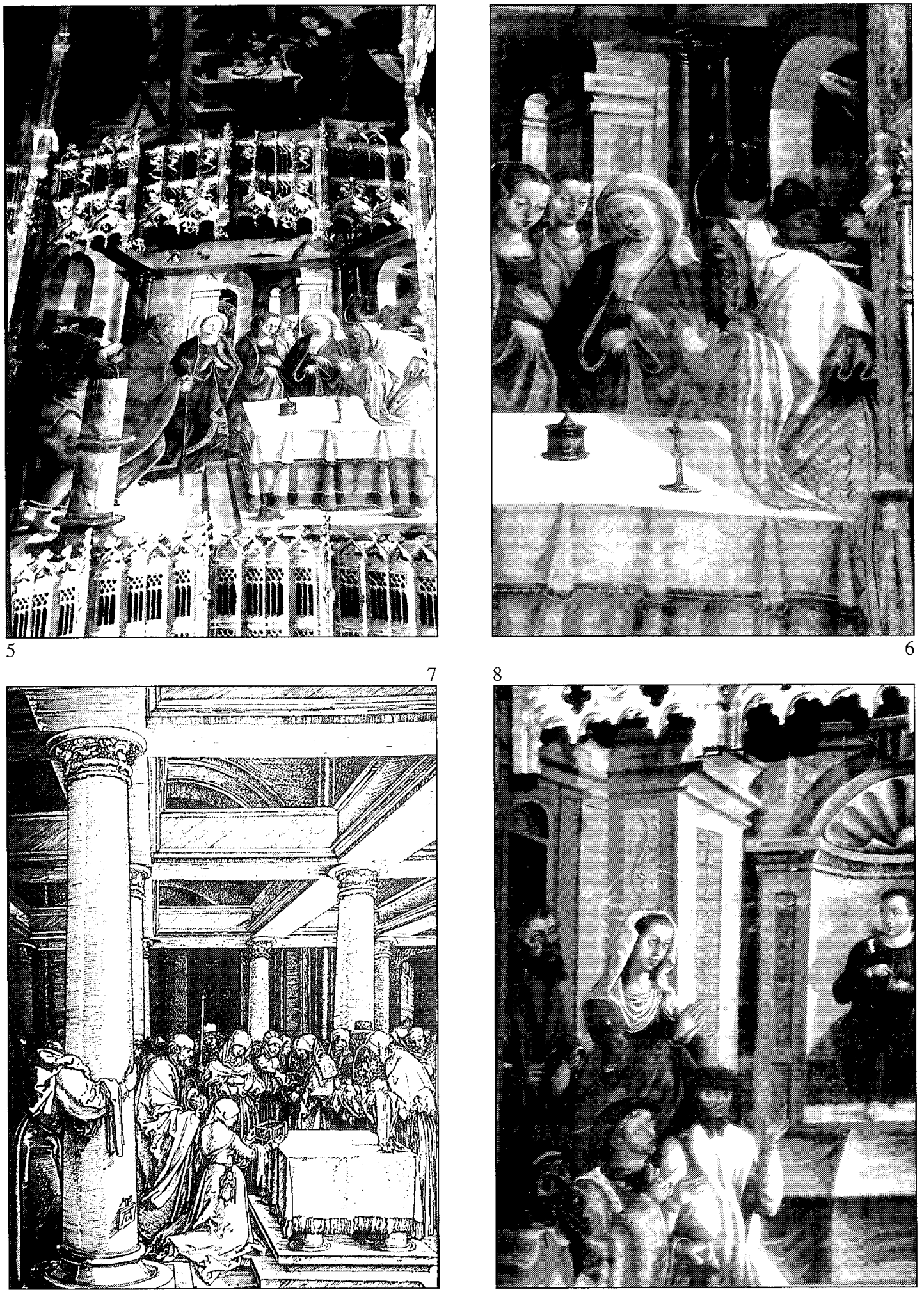

Figs. 5 y 6. Maestro de los Santos Juanes: Presentación en el templo y detalle del mismo. Cisneros (Palencia). Fig. 7. Durero: Presentación en el templo.

Fig. 8. Maestro de los Santos Juanes (taller): Jesús entre los doctores (detalle). Cisneros (Palencia). 
personaje en la Presentación del Niño en el templo del catálogo de Caylus ${ }^{11}$. Para la escena de Presentación de la Virgen (fig. 4), se ha servido de una estampa de Durero sobre el mismo tema perteneciente a su serie de grabados sobre la vida de María (fig. 3). El pintor ha sintetizado al máximo la composición del artista alemán, dejando en la parte baja de la escalera al grupo principal, formado por los Padres de la Virgen y otra pareja de ancianos, facilmente reconocibles en el grabado de Durero. La arquitectura dureriana se ha simplificado mucho, pero respeta la composición general de la misma: en las dos escenas se abre al fondo sobre el muro un arco de medio punto que deja ver el paisaje. Las mayores variaciones las encontramos en la Virgen, que se encuentra al lado del sacerdote Zacarías en vez de en la parte baja de la escalera. Los personajes más afines a la estética del maestro de los Santos Juanes son Santa Ana y el anciano situado tras ella, que nos presenta otro de los tipos distintivos de este maestro anónimo, ancianos de largas y pobladas barbas que encontramos en casi todas sus tablas. Otros personajes que coinciden en su caracterización son el sacerdote Zacarías de la tabla de Campazas y el San José situado en un segundo plano tras la Virgen en la Presentación de Jesús de la galería Caylus.

Los retablos que a continuación queremos analizar se hallan en tres provincias diferentes, todas castellano-leonesas, que tienen la peculiaridad de encontrarse en Tierra de Campos y de haber dependido en el pasado de la diócesis de León.

Quizá el retablo más polémico de los tres y que cuenta con más bibliografía es el mayor de la parroquia de San Facundo y San Primitivo en Cisneros (Palencia). Prácticamente desde la creación de la figura del Maestro de Astorga ha sido incluido entre sus obras ${ }^{12}$. En los últimos años se ha matizado esta afirmación, llegándose a la conclusión de la participación de otros pintores en diversas tablas del retablo ${ }^{13}$. La parte correspondiente al lado del Evangelio pertenece a un maestro o maestros diferentes y con menos talento que el Maestro de Astorga. En el lado de la Epístola, que contiene las escenas de la Entrada en Jerusalén, Última Cena, Oración en el Huerto, Prendimiento, Flagelación, Coronación de espinas, Camino del Calvario, Descendimiento de la Cruz, Resurrección y en el banco San Juan Evangelista, Saúl y Jonás, Ezequías y Samuel y David, reconocemos el buen hacer del mismo artista que en el retablo de la Pasión de la catedral de Astorga. Pero la inferior calidad de las tablas del lado del Evangelio no se puede atribuir simplemente a la participación del taller, sino que contemplamos la obra de un pintor con un estilo que tiene puntos en común con el Maestro de Astorga pero que posee una personalidad propia. Las escenas de este lado son: Anunciación, Nacimiento, Adoración de los Magos, Presentación en el templo, Jesús entre los Doctores, las Bodas de Caná y en el banco Elias, Salomón y Daniel, Balaam y Moisés y San Juan Bautista ${ }^{14}$. Creemos hallar la mano del Maestro de los Santos Juanes en la Presentación en el templo (figs. 5 y 6) y quizá en la Adoración de los Magos (fig. 9), además de en la parte correspondiente en el banco ${ }^{15}$. Las dos escenas narrativas vuelven a acudir a la serie de grabados de Durero sobre la

\footnotetext{
11 Op. cit, 1997, pp. 36-37.

12 Angulo Íñguez, Diego: «Varios pintores de Palencia. El Maestro de Astorga» Archivo Español de Arte, 1945, p. 231; POST, Raymond Chandler: A History of Spanish Painting, vol X, 1950, pp. 447.-449

${ }^{13}$ Díaz Padrón, Matías; Seguí, Mónica: «EI Maestro de Astorga: nuevas tablas inéditas o poco conocidas en colecciones españolas y extranjeras» Archivo Español de Arte, 1989, p. 346; Padrón Mérida, Aída: «Pintura del XVI en "El contrapunto y su morada". Nuevas atribuciones y valoraciones» Antiquaria, n. ${ }^{\circ} 117,1994$, pp. 72-78. Fernández del Hoyo, M. Antonia; Cisneros. Iglesia de San Facundo y San Primitivo. Palencia, 1993, pp. 33-34.

14 Fernández del Hoyo, M.* Antonia, $O$ p. cit, p. 28, la autora apunta que el retablo ha sufrido modificaciones, que ella sitúa en la segunda mitad del xvi. La ausencia de pinturas en el paño exterior del lado de evangelio, además de otros muchos detalles así nos lo indican. Presumiblemente, estas tres tablas que faltan se dedicarían a relatar la infancia de Cristo, como el resto de las pinturas de este lado del retablo; escenas habituales y que están ausentes aquí son la Huida a Egipto, Circuncisión, Adoración de los pastores. Tampoco hubiera sido extraña la inclusión del Bautismo de Cristo.

15 Salvo en el profeta Elías, que es de fecha posterior.
} 

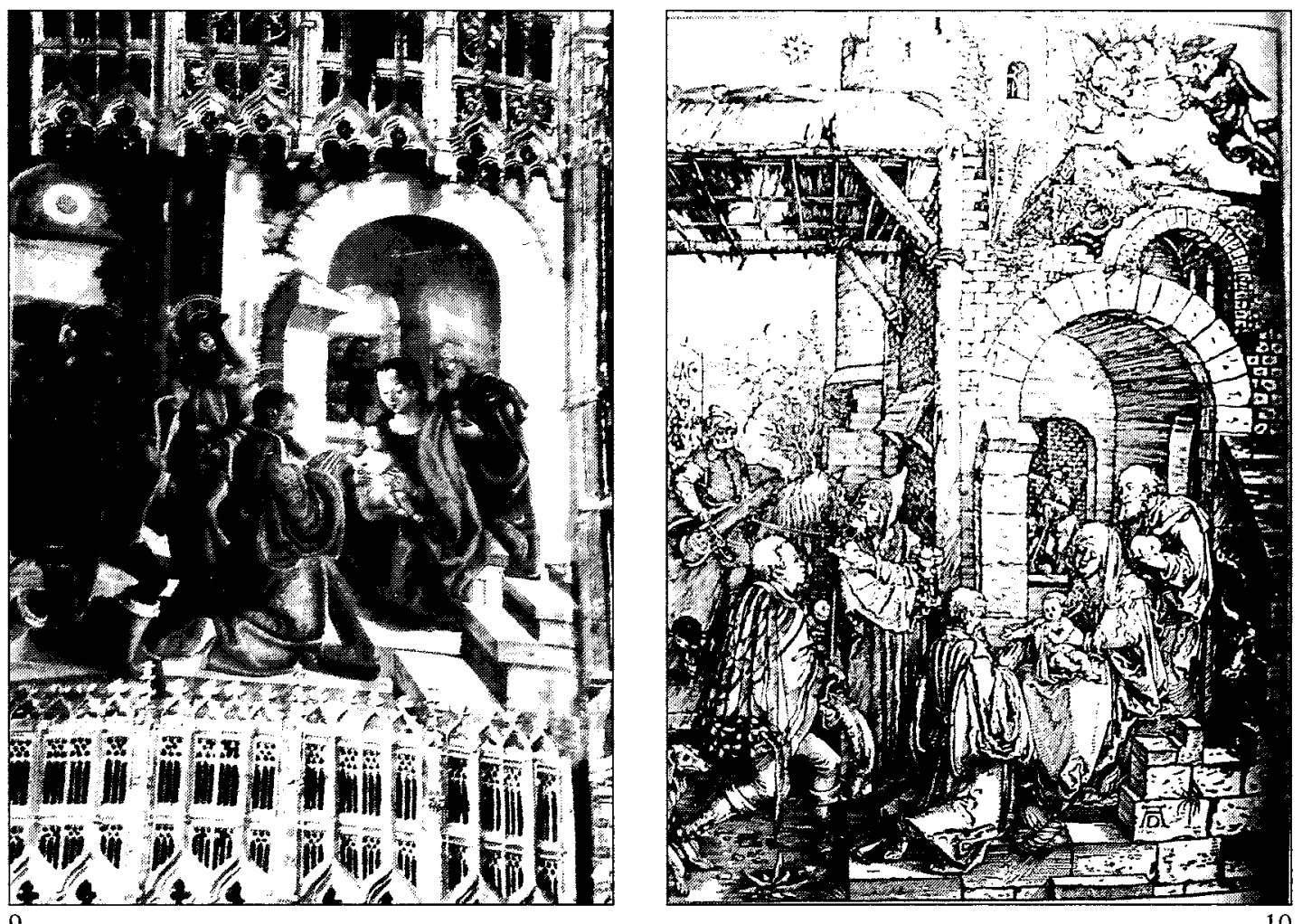

Fig. 9. Maestro de los Santos Juanes: Adoración de los Reyes Magos. Cisneros (Palencia). Fig. 10. Durero: Adoración de los Reyes Magos.

vida de la Virgen. La Presentación en el templo reproduce el grabado homónimo con gran exactitud (fig. 7), pero con una mayor pobreza de recursos; da la impresión de que el pintor soluciona los escollos causados por su impericia eliminando todo aquel elemento que no le haga sentir seguro a la hora de elaborar la composición. Así, la columna en primer plano aparece truncada, y la cubierta adintelada se sustituye por un sencillo entramado de madera. Más fiel es la interpretación que hace de la estampa homónima en la Adoración de los Reyes (fig. 10): cambian los ropajes y algún detalle arquitectónico. Respecto a las fuentes iconográficas del banco, se ha incidido en la inspiración en los reyes del banco de Santa Eulalia de Paredes de Nava y en el retablo mayor de la catedral de Palencia ${ }^{16}$. Esta doble tendencia ilustra muy gráficamente la confluencia de estilos de los dos grandes pintores que se da en la pintura palentina y su irradiación en Tierra de Campos. La atribución al Maestro de los Santos Juanes se justifica por la reiteración de los personajes; baste comparar a Simeón en la tabla de Cisneros y en la del Catálogo de Caylus, o con varios de los apóstoles de la Última Cena de dicho catálogo. Lo mismo sucede con los rostros del banco, siendo el más representativo el del profeta Balaam (fig. 11), que repite los rasgos anteriormente citados. Más problemática se presenta la atribución de la Epifanía. La calidad es inferior, aunque dentro del estilo de este maestro. Por ejemplo, el rey arrodillado tiene los mismos rasgos que Judas en la Última Cena de Caylus.

\footnotetext{
${ }^{16}$ Fernández del Hoyo, M. ${ }^{a}$ Antonia: Op. cit. Además de la inspiración que señala la autora entre en el Salomón de Paredes de Nava y el mismo rey de Cisneros y la de Pilatos del retablo mayor de la catedrál palentina con el profeta Daniel de Cisneros, apuntada por Julia Ara en la ficha sobre esta tabla del banco para el catálogo de Las Edades del Hombre de Salamanca (El contrapunto y su morada, Salamanca, 1993, pp. 134-135, n. ${ }^{\circ} 65$ ), encontramos clara inspiración del retablo paredeño en otros profetas del banco pertenecientes al lado realizado por el Maestro de Astorga. El rey David de Paredes inspira a Ezequías, mientras que el Saúl de Cisneros está basado en Esdrás.
} 

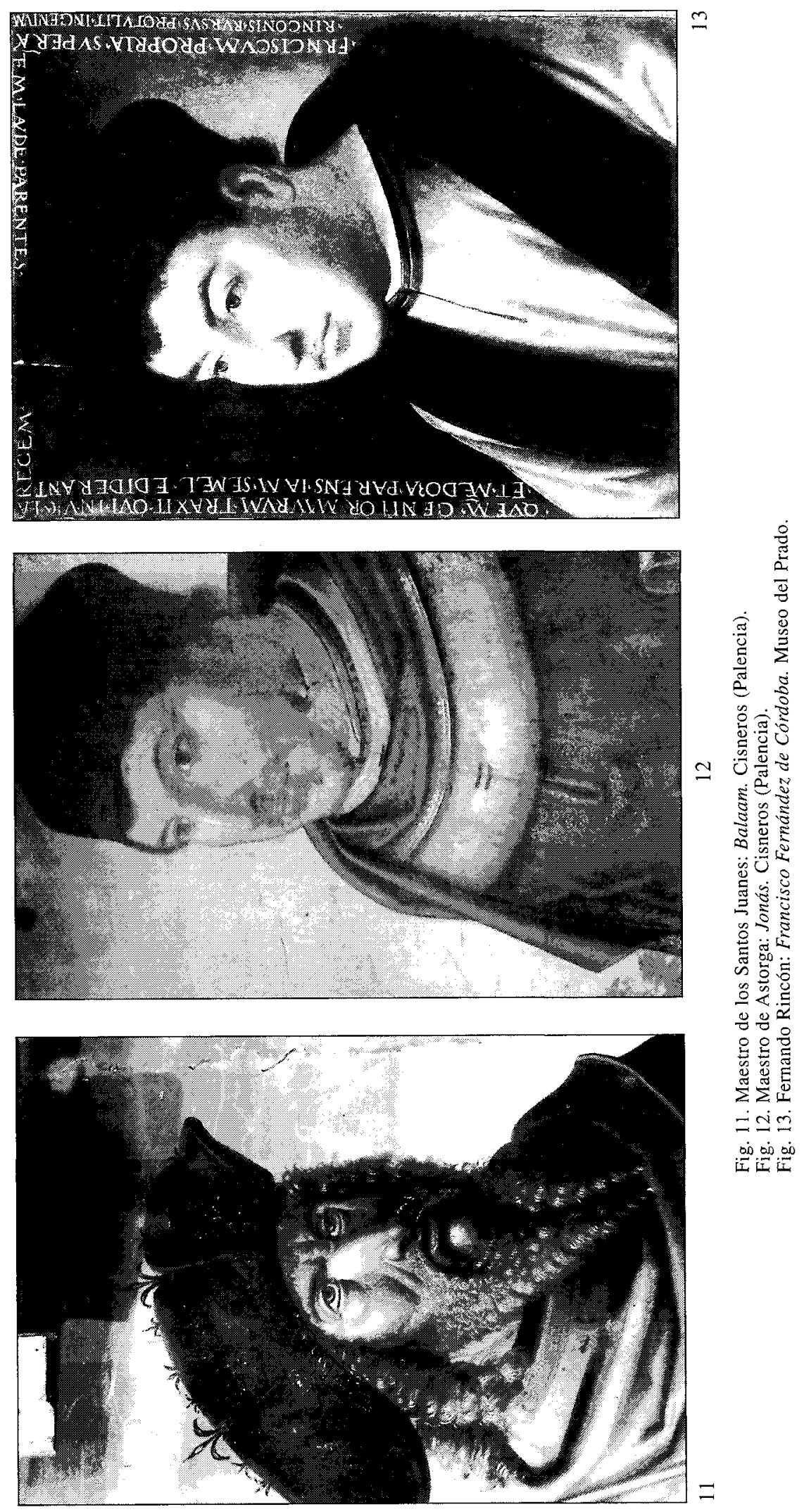
Pero hay que tener en cuenta que puede haberse inspirado directamente en el citado grabado de la Epifanía en el que el rey ostenta el mismo perfil.

Percibimos una mano muy diferente en la Anunciación y en la Natividad ${ }^{17}$, que también se inspiran fielmente en los correspondientes grabados de Durero sobre la Vida de la Virgen. Por último, las escenas de Jesús entre los doctores (fig. 8) y Las Bodas de Caná, son las de peor calidad, pero se reconoce la misma sensibilidad, por lo que estimamos que son obras de taller. Volviendo a las tablas que hemos considerado realizadas por el Maestro de los Santos Juanes, pese al reconocimiento de los tipos humanos, se nota una mayor torpeza compositiva que en las tablas del catálogo de Caylus. Pensamos que esto se debe a que se trata de una obra de juventud que se puede fechar a finales de la década de los veinte. Esta suposición la apoyan varios datos; en primer lugar, las propias tablas del maestro. Isabel Mateo fecha por el ropaje y el estilo las tablas que comenta en $15388^{18}$; como veremos más adelante, contamos con otra fecha, 1542 , en un retablo perteneciente al mismo maestro, pero de estilo mucho más avanzado: el de San Felipe y Santiago el Menor en Mayorga de Campos (Valladolid). Es decir que la evolución intrínseca de la obra del pintor nos hacen suponer que ésta sea una de sus primeras obras, ya con un estilo definido, pero aún lastrada por la inexperiencia. Además, hay que tener en cuenta el ensamblaje del retablo, gótico. Este tipo de ensamblajes, aunque perduran largo tiempo en Tierra de Campos, no se mantienen más allá del inicio de la cuarta década del siglo xvi. Por último, otro factor muy interesante a tener en cuenta nos lo proporciona la parte del retablo correspondiente al Maestro de Astorga. Aparte de que la actividad de este pintor hay que centrarla entre las décadas de los diez y los treinta, en el banco encontramos en el profeta Jonás (fig. 12) la reproducción del retrato que Fernando Rincón hizo de Francisco Fernández de Córdoba y Mendoza, tercer hijo del segundo Conde de Cabra. El retrato de Rincón, hoy en el Museo del Prado (fig. 13), se fecha pasado el año de 1520. El retratado, tras ocupar las sillas episcopales de Oviedo y Zamora, fue obispo de Palencia entre 1534 y $1536{ }^{19}$. Es muy tentador establecer relación entre el episcopado de Mendoza y su retrato en este retablo, pero la parroquia de San Facundo y San Primitivo dependía del desaparecido monasterio de Benevívere, y aparte de esta dependencia, ya se ha dicho que Cisneros pertenecía a la diócesis leonesa en el siglo XVI, por lo que no parece adecuada su vinculación con el obispado de Palencia. Por otro lado, las fechas de 1534-1536 son demasiado tardías para el retablo, tanto por la arquitectura del mismo como por el estilo de las pinturas. Pensamos que la hipótesis más razonable es la del conocimiento del Maestro de Astorga del retrato y su reproducción, pero dotando a la figura de una mayor edad, en este retablo, que sería por tanto posterior a 1520. La copia de Pilatos del retablo mayor de la catedral de Palencia en el profeta Daniel ${ }^{20}$ también nos sirve para matizar la fecha. A tenor de la documentación conservada, las tablas de Juan de Flandes no fueron colocadas antes de $1522{ }^{21}$, por lo que difícilmente pudieron ser objeto de inspiración antes de esa fecha.

En Villarrín de Campos (Zamora) en la parroquia de la Asunción de la Virgen, el retablo mayor barroco alberga 12 tablas del siglo xvi, probablemente aprovechadas del antiguo retablo mayor. Narran la vida de la Virgen, sin guardar un orden cronológico, en las siguientes escenas: Rechazo de la ofrenda de San Joaquín, Anuncio del ángel a San Joaquín, Anuncio del ángel a Santa Ana, Abrazo ante la Puerta Dorada, Nacimiento de la Virgen, Desposorios de la Virgen y

\footnotetext{
17 Martínez González, Rafael: Catálogo de la exposición: Raíces. El arte en Palencia. Palencia, 1989. Atribuye la Natividad a Juan de Tejerina. Aunque la impronta de Juan de Flandes es más pura que en el resto de las tablas, la comparación de tipos con los de tablas seguras de Tejerina, nos impide compartir esa hipótesis.

${ }^{18}$ Mateo Gómez, Isabel, Op. cit., 1993.

19 Fernández de Madrid, Alonso: Silva Palentina. Palencia, 1976, p. 467.

20 Ara Gil, Julia: Op. cit.

21 Vandevivere, Ignace: Catálogo de la exposición: Juan de Flandes. Madrid, Museo del Prado, febrero-marzo 1986, p. 90
} 


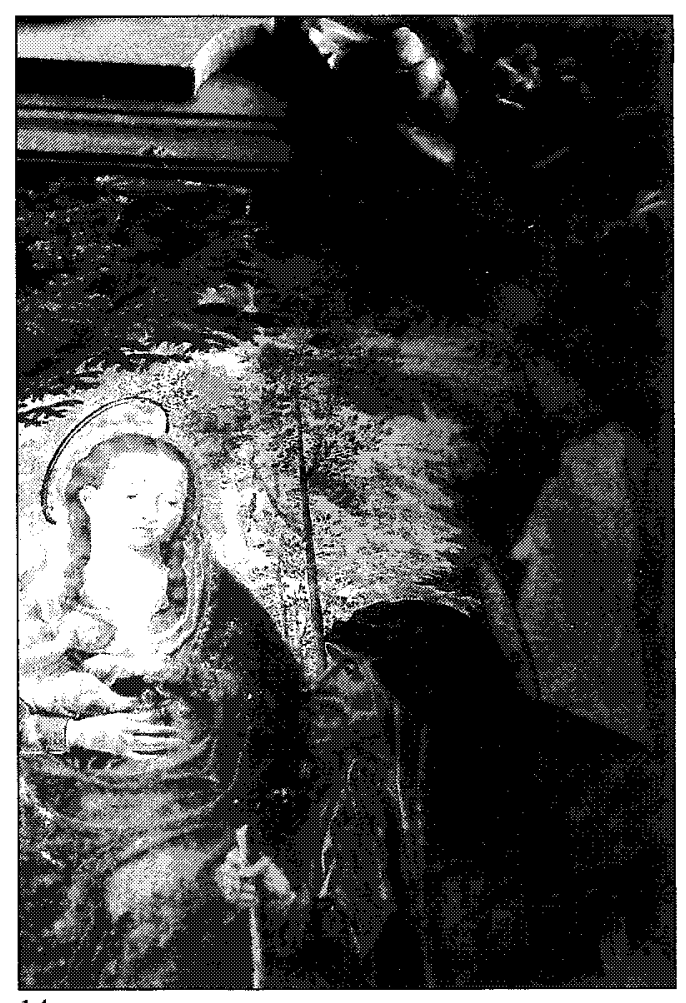

14

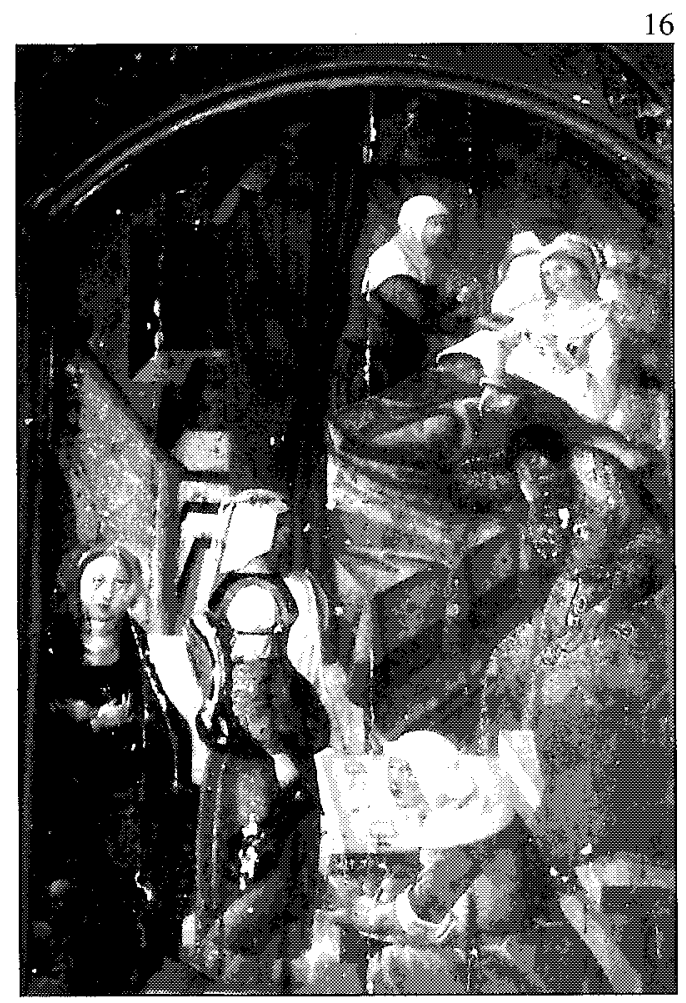

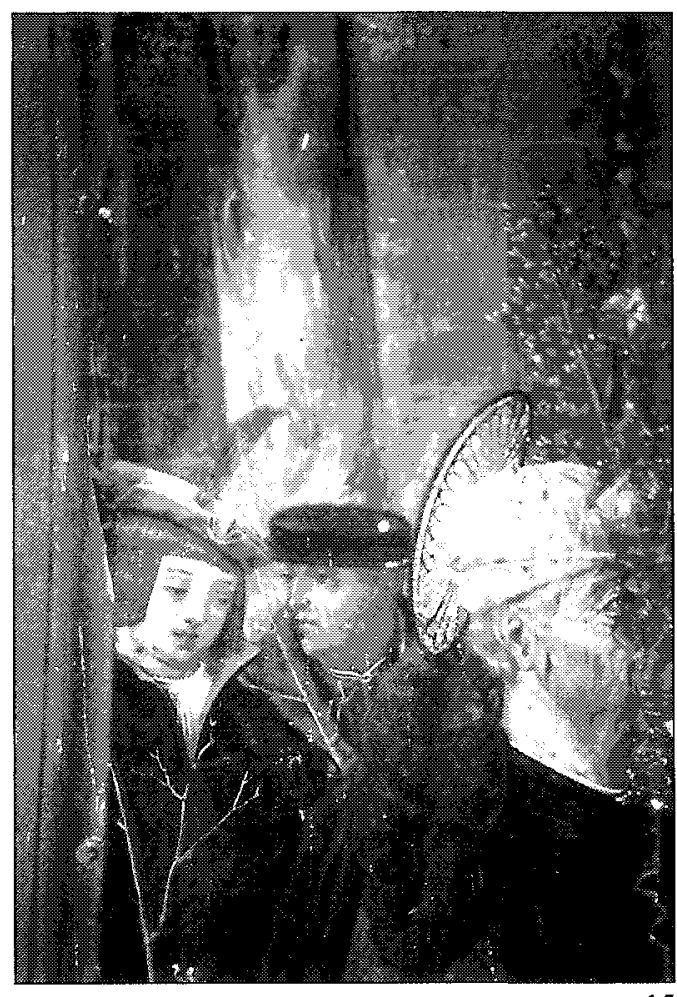

15

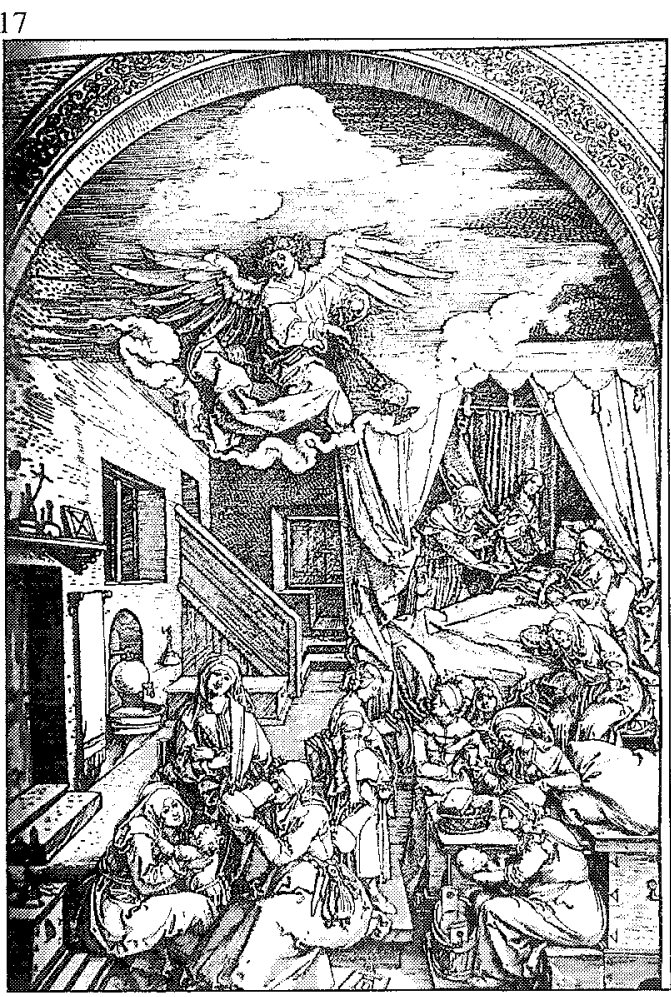

Figs. 14 y 15. Maestro de los Santos Juanes: Huida a Egipto (detalle); Desposorios (detalle). Villarrín de Campos (Zamora) Fig. 16. Maestro de los Santos Juanes (taller): Nacimiento dela Virgen. Villarrín de Campos (Zamora). Fig. 17. Durero: Nacimiento de la Virgen. 
San José, Visitación, Natividad, Epifanía, Huida a Egipto, Presentación en el templo y Circuncisión. De nuevo hallamos puntos de contacto con el Maestro de Astorga, en los paisajes sobre todo y en los rostros de algunos personajes. Por eso consideramos que la escena de la Natividad sería obra suya o de su taller. La dulzura del rostro de la Virgen concuerda con el estilo delicado del Maestro de Astorga más que con el Maestro de los Santos Juanes, cuyos rostros femeninos son mucho más adustos. Los semblantes masculinos del resto de las tablas son inequívocamente del de los Santos Juanes. Los ancianos, con sus rostros barbados y expresivos perfiles, como San José en la Huida a Egipto (fig. 14), los hebreos de la Circuncisión o Zacarías en La Visitación. Los jóvenes imberbes con la dulzura un tanto afeminada, como el rey Gaspar o el joven tocado con un sombrero con pluma (fig. 15) de los Desposorios detrás de San José. La tabla del Nacimiento de la Virgen (fig. 16), de nuevo inspirada en el grabado de Durero sobre el mismo tema (fig. 17), es de inferior calidad, lo cual está acentuado por el lamentable estado de conservación de las tablas y por los repintes. Pese a ello, reconocemos el rostro de Santa Ana; es el mismo que el de la Virgen en la escena de Jesús entre los doctores de Cisneros y que el de la mujer a la izquierda de San Juan en Las bodas de Caná de dicho retablo.

En Mayorga (Valladolid), a medio camino entre Cisneros y Villarrín, contamos con otro claro ejemplo de la obra del Maestro de los Santos Juanes. Se trata del retablo dedicado a San Felipe y Santiago el Menor ${ }^{22}$. Proveniente de la iglesia de Santa Marina, hoy ocupa el altar mayor en la iglesia de El Salvador. Ambos apóstoles presentan en las tablas un rostro similar. Debido a su condición de obispo de Jerusalén, Santiago puede llevar hábitos episcopales, pero en esta ocasión el pintor ha optado por caracterizarlo con una túnica, al igual que a San Felipe. Quizá por este motivo y por la poca extensión de su culto en esta zona no haya sido advertida hasta ahora la doble advocación del retablo. Al margen de sus diferentes relatos, la distinción entre ambos santos la proporciona el atributo de San Felipe, una cruz atada al extremo de una vara. Las diez tablas que lo componen se reparte en cuatro calles y dos cuerpos más un banco; en las calles centrales hay dos nichos que albergan las esculturas dieciochescas de Santa Águeda y Santa Catalina ${ }^{23}$, que en su origen estarían ocupados por las estatuas de los santos titulares. San Felipe y Santiago el Menor aparecen usualmente vinculados, ya que su fiesta se celebra el mismo día. De las diez pinturas, cinco se dedican a narrar la historia de cada apóstol, pero no guardan un orden cronológico ni se reserva una mitad del retablo para cada uno, por lo que es muy probable que se haya trastocado su disposición original. En La leyenda dorada de Santiago de la Vorágine se nos narra que Felipe, durante su predicación en Escitia, fue obligado a adorar una estatua del dios Marte; cuando estaba siendo coaccionado, de debajo de la estatua surgió un dragón que con su hedor mató al hijo del sumo sacerdote que custodiaba el templo pagano y a dos tribunos encargados de la vigilancia del apóstol. Los paganos le prometieron destruir la estatua de Marte y poner en su lugar una cruz si restituía a la vida a los tres fallecidos; seguidamente San Felipe ordenó al dragón que se marchara y las tres personas resucitaron. Un tiempo después el apóstol se marchó a la ciudad de Hierápolis, en Asia Menor, donde fue crucificado ${ }^{24}$. Respecto a la vida de Santiago el Menor o Santiago Alfeo, Santiago de la Vorágine relata que, tras la partida de San Pedro para Roma, Santiago fue consagrado obispo de Jerusalén; durante la Pascua, los judíos le instaron a que desengañara a la multitud de su creencia de que Jesucristo era el Mesías esperado, pero él proclamó que Jesús era el hijo de Dios. Enfurecidos los judíos, le

\footnotetext{
${ }^{22}$ Urrea Fernández, Jesús; Brasas Egido, José Carlos: Catálogo Monumental de Valladolid, Antiguo partido judicial de Villalón. Valladolid,1981, p. 66, lo vinculan solamente con la vida de San Felipe, al igual que Rodicio, Cristina: Pintura del siglo xvı en la Diócesis de León. León, 1985, p.59.

23 Urrea Fernández, Jesús; Brasas Egido, José Carlos: Op. cit.

${ }^{24}$ Santiago de la Vorágine: La leyenda dorada, t. I, Madrid, 1996, p. 277.
} 

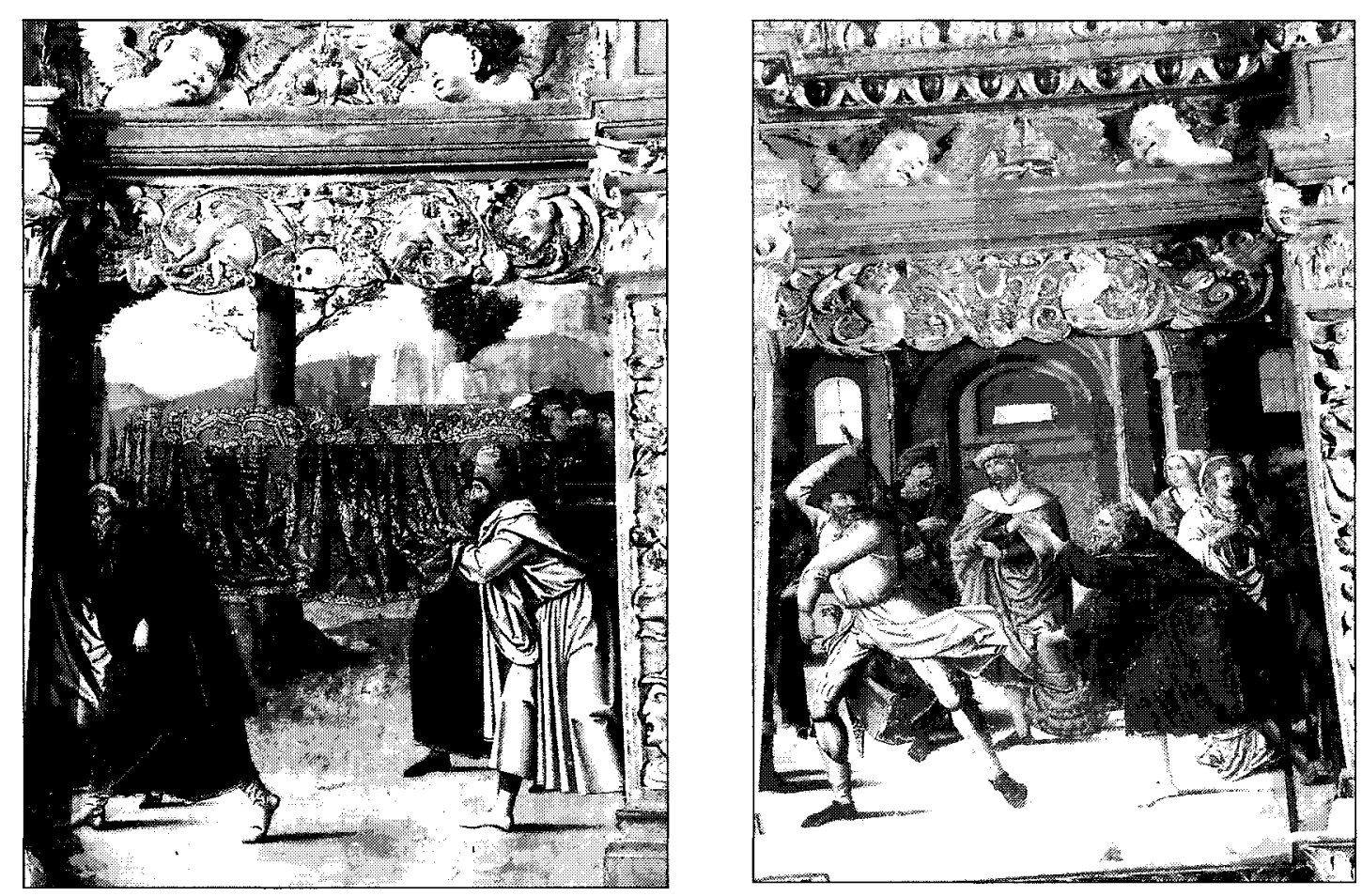

18

20
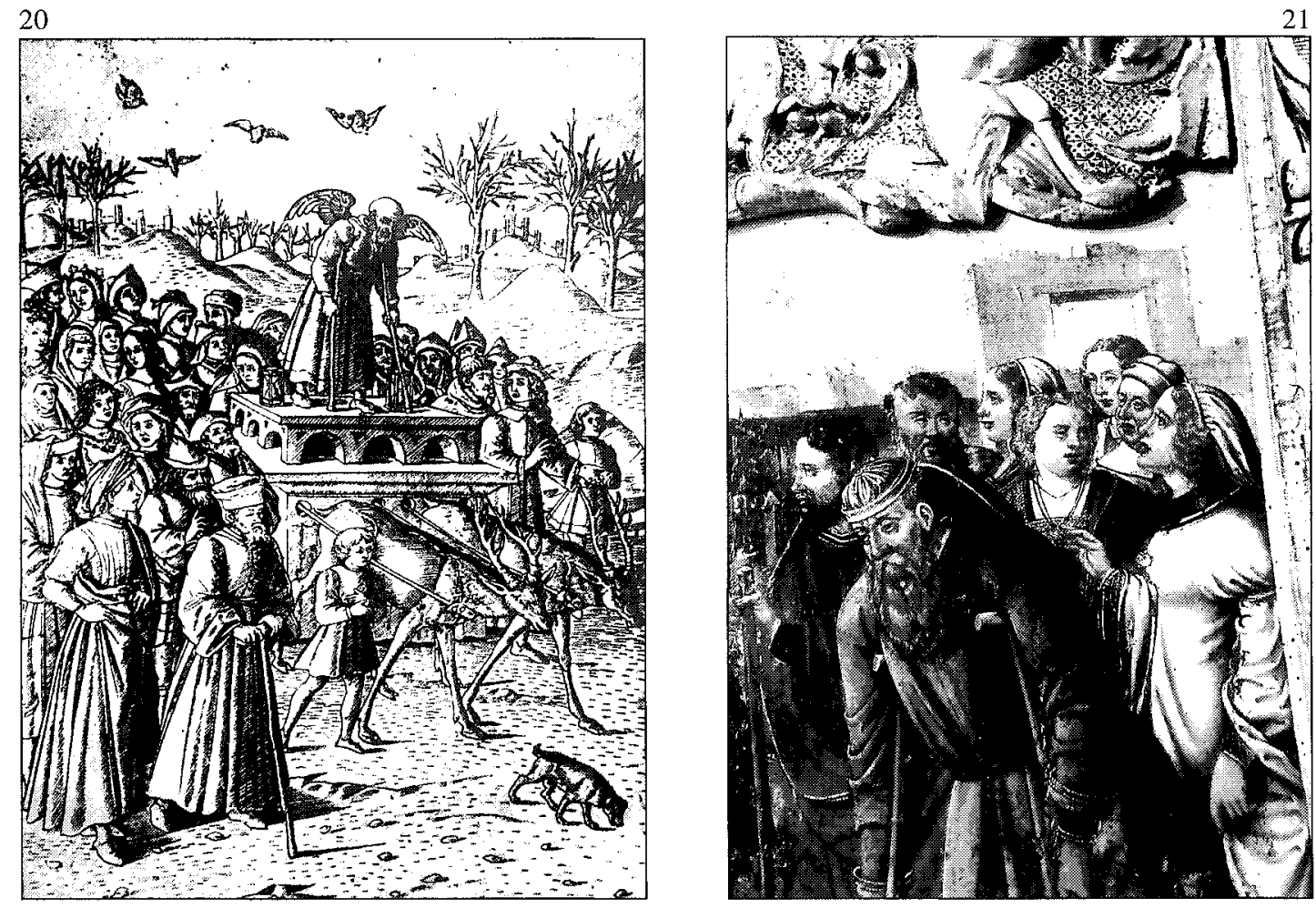

Figs. 18 y 19. Maestro de los Santos Juanes: Traslado del cuerpo de Santiago el menor y Martirio de Santiago el menor: Mayorga (Valladolid).

Fig. 20. Nicoletto de Modena: Triunfo del Tiempo.

Fig. 21. Maestros de los Santos Juanes: Prendimiento de San Felipe (detalle), Mayorga (Valladolid) 
arrojaron desde el púlpito en el que predicaba, le apedrearon y un batanero le rompió el cráneo con su garrote ${ }^{25}$.

En el banco encontramos de izquierda a derecha, el Prendimiento de San Felipe, Muerte de tres paganos por el hedor del dragón, en la tercera escena se increpa a San Felipe a adorar una estatua de Marte, y en la cuarta y última del banco San Felipe resucita a las tres personas que había matado el dragón; el primer cuerpo empieza con una escena de difícil interpretación iconográfica: representa el traslado por cuatro hombres de un bulto cubierto con una tela brocada, que se puede interpretar como un ataud (fig. 18). La leyenda de oro nos narra que tanto el cuerpo de San Felipe como el de Santiago el Menor fueron trasladados a Roma con posterioridad a su muerte ${ }^{26}$. Puesto que no hay ningún símbolo alusivo a ninguno de los dos apóstoles, pensamos que se trata de una escena de la vida de Santiago, ya que de este modo se equilibran el número de tablas dedicadas a cada santo. En la siguiente historia de este cuerpo, separada de la anterior por los dos nichos para escultura que hemos mencionado antes, San Felipe ordena al dragón que se aleje. El segundo cuerpo se dedica por entero a la vida de Santiago, empezando por su Predicación, siguiendo con su Detención, Martirio con el garrote de un batanero y por último Santiago arrojado del púlpito en el que predicaba. El pintor ha evitado las escenas crueles de martirio. En el caso de Santiago nos muestra al verdugo un momento antes de golpear al santo (fig. 19); mientras que en la historia de San Felipe ni siquiera asistimos a su crucifixión.

Se ha apuntado su filiación con la pintura renacentista leonesa, en concreto con el círculo de Francisco de Carrancejas ${ }^{27}$ y con Cristóbal de Colmenares ${ }^{28}$. Creemos que se debe al mismo pintor que realizó las tablas de los Santos Juanes. Sería prolijo enumerar los paralelismos entre todas las tablas y las atribuidas por Isabel Mateo, pues en todas ellas hallamos grandes coincidencias. Por el estilo de las tablas, ésta sería la obra más cercana al retablo de los Santos Juanes que da nombre al pintor. Por otra parte, como se apuntaba más arriba, contamos con otra fecha, 1542, inscrita en una cartela en el fuste de la columna con grutescos de San Felipe resucita a las tres personas que había matado el dragón, lo que unido a su estilo avanzado nos ayuda a catalogar el retablo como la más madura de todas las obras de las conocidas hasta ahora.

Si observamos las tablas es palpable la evolución que ha sufrido su estilo desde los anteriores retablos. En las tablas de Mayorga se aleja del toque quattrocentista que aún se percibe en Cisneros y Villarrín. Los paisajes aún dependen de la escuela umbra del siglo xv, pero en los interiores arquitectónicos demuestra su conocimiento de grabados, probablemente de Raimondi, a partir de la obra de Rafael. Esta impronta rafaelesca es patente también en el dinamismo que imprime a los personajes a través de expresivas posturas de las manos, escorzos y cabellos al viento. En esta obra además, vuelve a demostrar su gran interés por el espacio, que maneja con más soltura que en las tablas de los retablos anteriormente vistos. La pregunta que surge es de dónde le viene este aprendizaje. La utilización de grabados de Rafael es una constante en la pintura del siglo xVI en España ${ }^{29}$, pero el avance que observamos en este pintor no es debido tan sólo al empleo de estampas italianas. Es un cambio más profundo que obedece a la observación de obras con este nuevo estilo, hechas por pintores españoles que viajaron a

\footnotetext{
25 Ibidem, pp. 281-282.

${ }^{26}$ La leyenda de Oro para cada día del año: vida de todos los santos que venera la Iglesia. Barcelona, 1865, t. II, pp. 6 y 7.

27 Urrea Fernández, Jesús; Brasas Egido, José Carlos: Op. cit.

28 Rodicio, Cristina: Op. cit.

29) Sobre este asunto v. Ávila Padrón, Ana: «Influencia de Rafael en la pintura y escultura españolas del siglo xvi a través de estampas», Archivo Español de Arte, LVII, 1984, pp.58-88.
} 

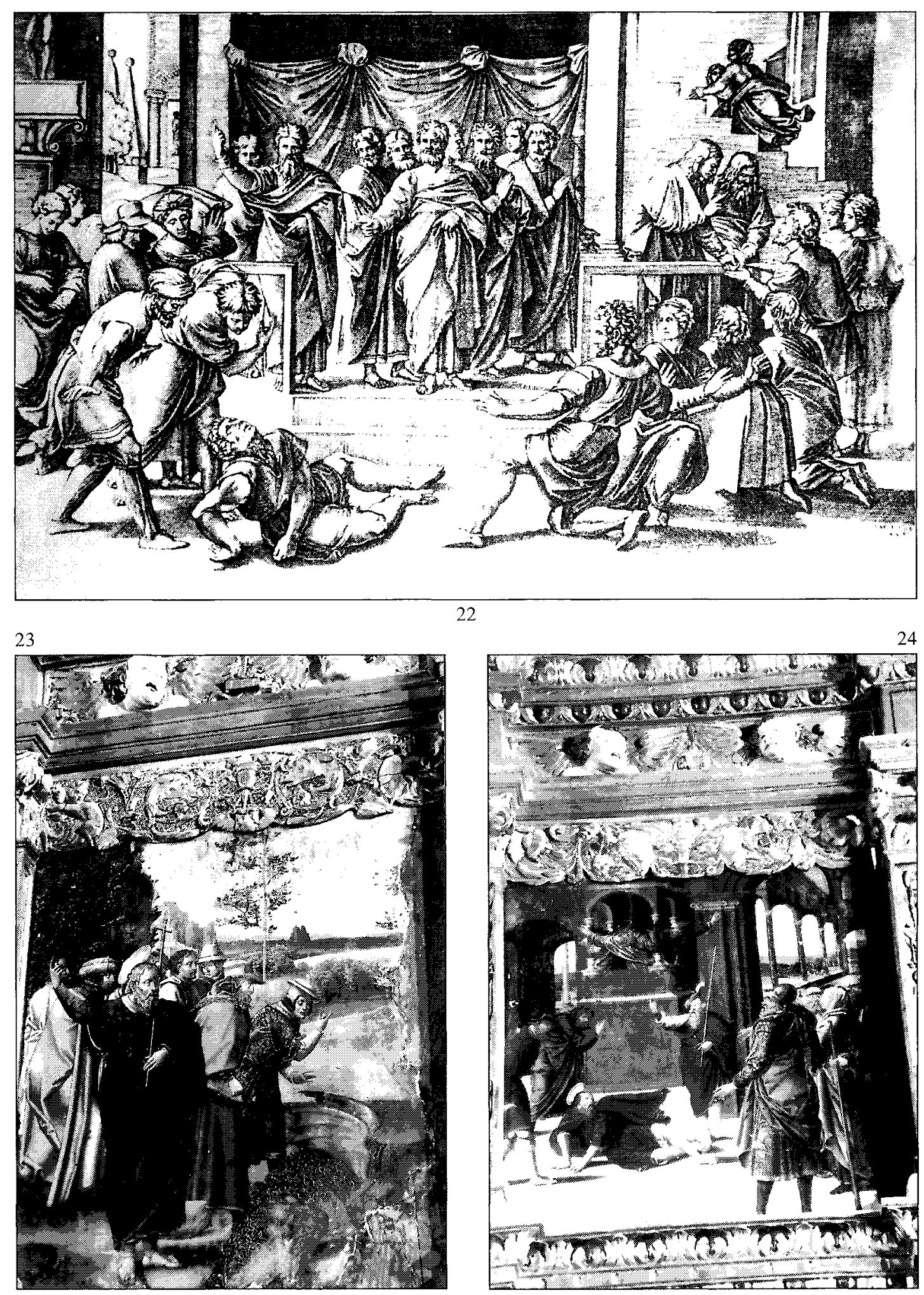

Fig. 22. Mercantonio Raimondi: Muerte de Ananias.

Figs. 23 y 24. Maestro de los Santos Juanes: San Felipe ordena al dragón que se aleje y Santiago arrojado del puilpito. Mayorga (Valladolid). 
Italia. La influencia del manierismo a través de Alonso Berruguete se deja sentir con fuerza en esta época en Tierra de Campos. Pero estas pinturas están lejos de la tensión dramática de la del palentino. Las figuras del Maestro de los Santos Juanes carecen de la ingravidez de las de Berruguete; tampoco encontramos el fuerte contraste lumínico utilizado por el paredeño. Por otro lado, el interés por los fondos arquitectónicos y paisajísticos del Maestro de los Santos Juanes no encuentran parangón en Berruguete y sus discípulos, que prefieren centrarse en la figura humana en primer plano, sin grandes composiciones de por medio. Nos parece que el manierismo rafaelesco de estas tablas debe más a Juan Soreda que a Berruguete por la propensión a hacer gala del conocimiento del repertorio renacentista en la arquitectura y en los ornamentos. Exista o no una influencia directa de Soreda, lo cierto es que el pintor conoce la obra de Rafael a través de estampas, pero, como se ha dicho, el empleo de grabados aparece más encubierto que en retablos anteriores. Aparte de grabados provenientes de Rafael, nuestro pintor parece haberse inspirado en la estampa de Nicoletto da Modena titulada «el triunfo del tiempo» (fig. 20) para el hombre con muletas del Prendimiento de San Felipe (fig. 21), que copia la personificación del Tiempo. Las escenas enmarcadas por arquitecturas responden a la utilización de grabados como El castigo de Elimas y La muerte de Ananías (fig. 22): situadas en interiores renacentistas, con un eje central en el que se desarrolla la escena principal, enmarcada por personajes secundarios a los lados cerrando la composición. Toma además posturas concretas de figuras de ambos grabados. Del segundo grabado citado, uno de los más utilizados en la pintura de la época, la figura a la derecha de San Pedro le sirve para el santo titular del retablo en San Felipe ordena al dragón que se aleje (fig. 23) y para el hombre que lleva una vara a la derecha del santo en Santiago arrojado del púlpito en el que predicaba (figs. 24 y 25); Santiago en esta escena reproduce con leves cambios la postura de Ananías (y la figura a su derecha, con manto verde, la correspondiente del grabado), al igual que el personaje que se incorpora del suelo en la tabla de San Felipe resucitando a los tres muertos por el dragón (fig. 26). En la citada tabla de San Felipe ordena al dragón que se aleje, observamos de nuevo el empleo de esta estampa en el joven con traje brocado a la izquierda de San Felipe: reproduce el gesto del personaje situado encima de Ananías en el grabado de Rafael, etc... Como vemos, este dinamismo superficial poco tiene que ver con el que dota Berruguete a sus figuras.

Como conclusión, nos hallamos ante un maestro de gran calidad, con un estilo muy personal, que sabe evolucionar a lo largo de toda su obra, que podríamos fechar entre la tercera y la quinta década de la centuria. Encontramos influencia sobre todo de Juan de Flandes y de maestros locales más humildes como el de Astorga. Esta doble influencia es patente sobre todo en el gusto por la espacialidad, por las atmósferas diáfanas, de luz matizada y por el amor al paisaje. Del maestro de Astorga toma además el procedimiento peruginesco a la hora de reflejar el paisaje. No es extraño que los estilos del Maestro de los Santos Juanes y del maestro de Astorga se hayan confundido en ocasiones. Pero el primero no es un mero seguidor de este último, con quien pudo haberse formado. Tienen puntos de contacto pero siguen caminos diferentes, y en obras conjuntas como la de Cisneros es patente la superioridad del de Astorga ante su rival más joven. La pertenencia de su obra a la antigua diócesis de León, y su vinculación estilística a Palencia, quizá permita acometer desde una perspectiva más amplia el estudio de la pintura leonesa de esta época.

Es también destacable su gran impronta norteña, que probablemente se deba en gran parte al uso de grabados de Durero. Los rostros de sus figuras se asemejan mucho a los de las estampas del maestro alemán, así como el aplomo en sus anatomías y el modo de tratar los contornos, de duros perfiles, como cincelados. Los pliegues de los ropajes son duros y marcados; frecuentemente dos largos pliegues paralelos discurren verticalmente a lo largo de las vestiduras. 


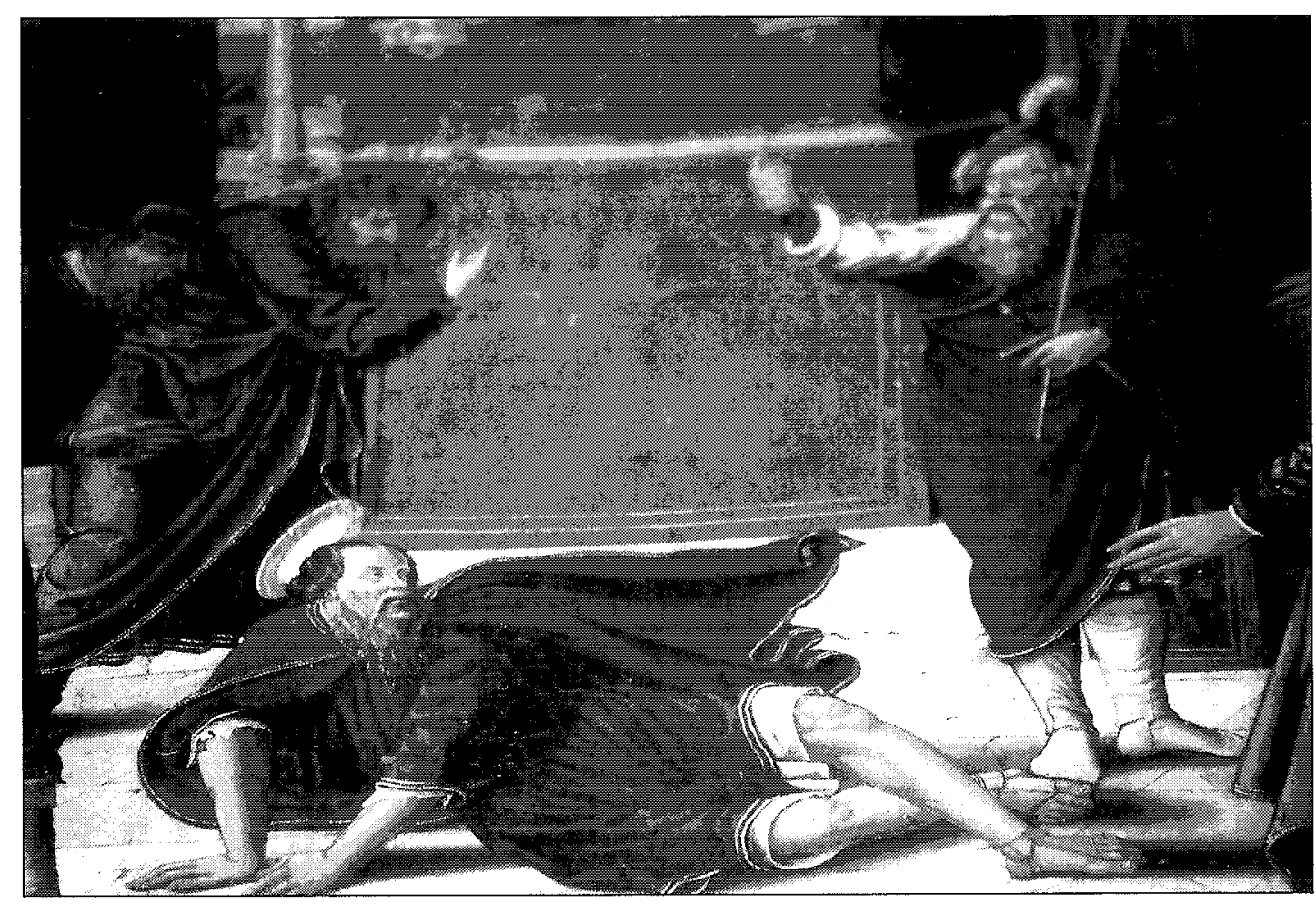

25

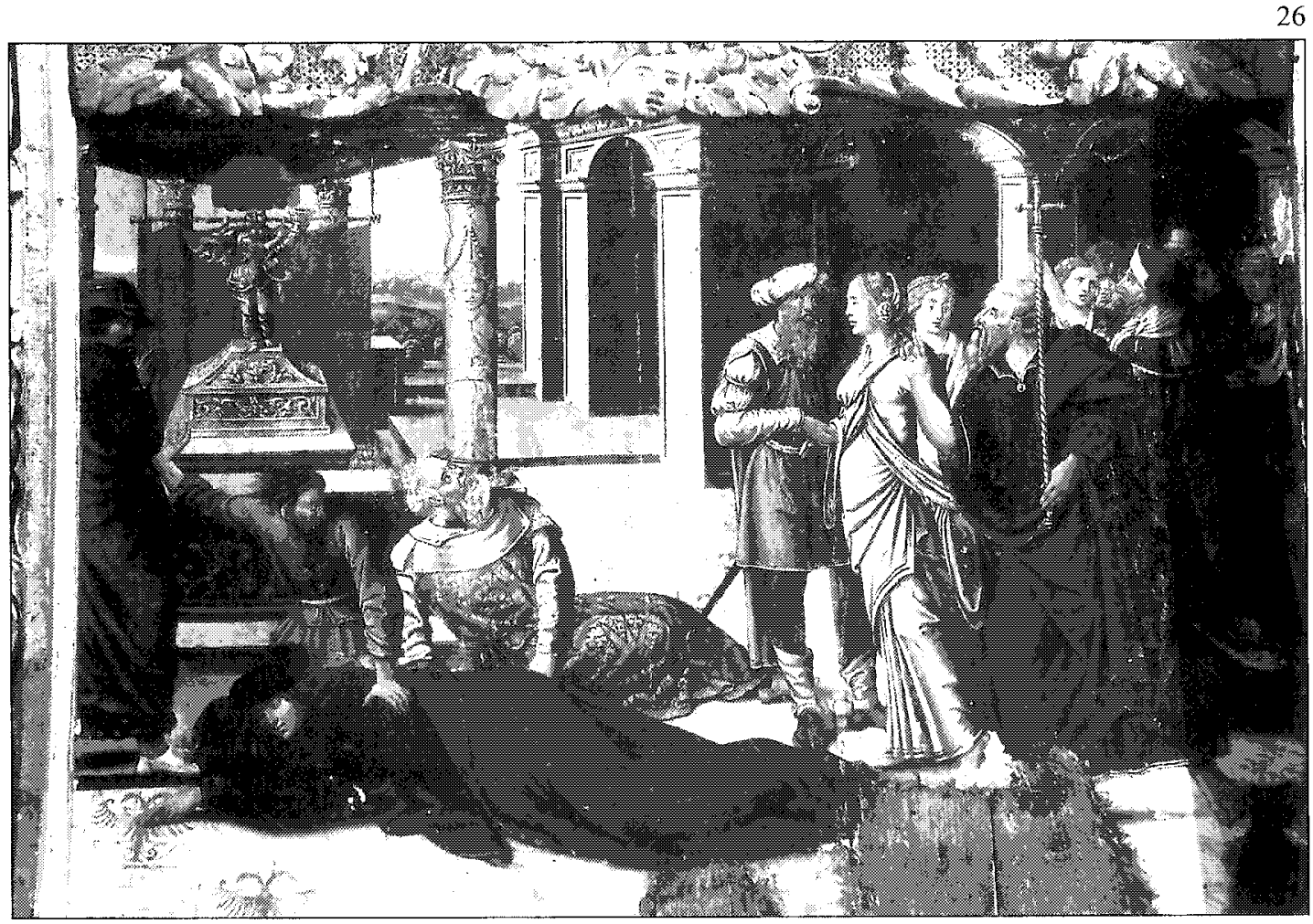

Fig. 25. Maestro de los Santos Juanes. Santiago arrojado del púlpito. Mayorga (Valladolid)

Fig. 26. Maestro de los Santos Juanes. San Felipe resucita a los tres muertos por el dragón. Mayorga (Valladolid). 
Estas características le acompañan en todas sus etapas. Aquello que cambia con el paso del tiempo es el desarrollo de la capacidad para desplegar una caja espacial más coherente, el aporte de las nuevas formas manieristas al movimiento de sus figuras y a la composición en general, además del empleo de las formas arquitectónicas del Alto Renacimiento italiano.

Esperamos que las investigaciones documentales, estériles hasta este artículo, nos permitan conocer algún día el nombre de este pintor. 